See discussions, stats, and author profiles for this publication at: https://www.researchgate.net/publication/350771865

\title{
Effects of High-Speed Versus Traditional Resistance Training in Older Adults
}

Article in Sports Health A Multidisciplinary Approach · April 2021

DOI: 10.1177/19417381211015211

CITATIONS

6 authors, including:

Itamar Pedro Vieira

Universidade Federal de Goiás

2 PUBLICATIONS OCITATIONS

SEE PROFILE

20. Rodrigo Ramirez-Campillo

Universidad de Los Lagos

385 PUBLICATIONS 4,137 CITATIONS

SEE PROFILE
READS

67

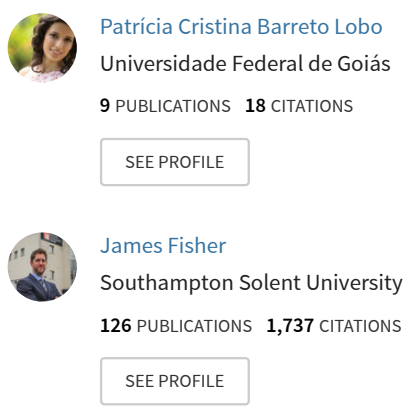

Some of the authors of this publication are also working on these related projects:

Project Estudio sobre desplazamiento activo y actividad física en población Chilena View project

Project beer and water consumption View project 


\section{Effects of high-speed versus traditional resistance training in older adults}

Background: The losses of strength, agility, balance and functionality caused by aging are harmful to the elderly population. Resistance training (TR) may be an efficient tool to mitigate such neuromuscular decline and different RT methods can be used. Therefore, it is important to investigate the different responses to different training methods. Hypothesis: Eight weeks of traditional resistance training (TRT) are expected to promote similar results to high-speed training (HST) in physical functional performance (PFP) and quality of life in the elderly. Methods: Participants $(n=24)$ with a mean age of $67.8 \pm 6.3$ years completed eight weeks of RT. Participants were randomized into HST $(n=12)$ and TRT $(n=12)$. TRT involved training with 10-12 repetitions at controlled velocity until momentary muscle failure; while HST involved performing 6-8 repetitions at $40-60 \%$ of $1 \mathrm{RM}$ at maximum velocity. Pre-and posttraining, the participants were tested for: i) maximum strength in the $45^{\circ}$ leg press and chest press; ii) PFP in the 30-second chair stand, timed-up-and-go (TUG); and medicine ball throw test; and iii) quality of life. Results: Both groups improved muscle strength in the $45^{\circ}$ leg press, with greater increases for TRT (HST: $+21 \%$ vs. TRT: $+49 \%$, $\mathrm{p}=0.019)$. There was no change in chest press strength for HST $(-0.6 \%)(\mathrm{p}=0.607)$, but there was a significant increase for the TRT group $(+21 \%, \mathrm{p}=0.001)$. There was a similar improvement $(\mathrm{p}<0.05)$ for both groups in TUG (HST: 7\%; TRT: 10\%), chair stand (HST: 18\%; TRT: 21\%), and medicine ball throwing performance (HST: 9\%; TRT: 9\%), with no difference between groups $(\mathrm{p}=0.081-0.944)$. Emotional aspect significantly increased by $20 \%(\mathrm{p}=0.042)$ in HST and $50 \%(\mathrm{p}=0.043)$ in TRT. Conclusions: Both TRT and HST are able to promote improvements in functional performance in the elderly with greater in strength gains for TRT. Therefore, exercise professionals could choose based on individual characteristics and preferences. Clinical Relevance: The findings provide important insights into how healthcare professionals can prescribe HST and TRT, considering efficiency, safety and individual aspects.

Keywords: Muscle strength; plyometric exercise; muscle fatigue; activities of daily living; physical conditioning. 


\section{Introduction}

From 30 to 50 years of life, adults lose 5 to 10 percent of skeletal muscle

46 mass, and the losses rise to 40 percent more at 80 years ${ }^{19}$. Functional measures such as

47 strength, endurance and walking ability appear to follow a similar loss as muscle mass ${ }^{7}$.

48 In addition, as fast-twitch muscle fiber decrease with age, the ability to perform tasks

49 that require speed and power may become challenging for the elderly ${ }^{2}$.

50 Although reduction in strength-producing capacity, protein synthesis

51 (especially in type II fibers), functionality and aerobic capacity occur with advancing

52 age, high-intensity (high relative loads, low volume, momentary muscle failure and

53 speed-controlled repetitions) RT may slow or reverse these adverse effects ${ }^{20}$.

54 Therefore, the decreases in functional performance, muscle strength and mass may be

55 related to disuse and not an inevitable effect of aging ${ }^{18}$.

56 Exercise may be an important strategy to prevent or reverse the functional

57 declines that accompany aging ${ }^{18}$. Regarding training models, important benefits may be

58 obtained through low-volume, high relative loads and speed-controlled repetitions, total

59 training times of less than 60 minutes per week ${ }^{15}$.

60 However, the use of maximal intensity training (until near the momentary

61 muscle failure) for the elderly population has been questioned ${ }^{8,9,35,41}$, as it may not

62 promote additional neuromuscular gains and expose the elderly to unnecessary risks and

63 discomfort.

64

An alternative strategy may be the use of high speed training (HST) which

65 has been widely used and recommended for providing various benefits to the elderly

66 population ${ }^{10,16,23}$. HST has been advocated as an important strategy for this population ${ }^{9}$, 
67 due to its safety, possibility of improving functional capacities, reducing the incidence 68 of falls, and increasing the independence of this age group ${ }^{8,9,35}$.

69 Considering the benefits of physical exercise for older people, RT, whether

70 traditional or high-speed, may be an important tool to enhance independent and quality

71 living conditions for this population. However, few previous studies have actually

72 compared the results between TRT and HST in the promotion of physical functional

73 performance (PFP), making it difficult to decide which RT strategy to choose.

74 Moreover, the previous literature that compared TRT and HST did not control for

75 training effort (i.e. volitional failure) during $\mathrm{TRT}^{4,26}$, which seems to be a key factor for 76 these groups ${ }^{18}$.

77 Thus, research is needed to examine the two training models and provide 78 information about their outcomes and benefits in gains in muscle strength and 79 functional capacity. Therefore, the aim of this study was to investigate the effects of 80 TRT and HST on PFP, muscle strength and quality of life in the elderly.

\section{Methods}

84 Participants

Twenty-four volunteers of both genders (17 females and seven males) with

87 no prior RT experience ( $\geq 60$ years old) participated in the study. The participants were 88 invited through social media, direct invitation and by referrals from third parties. All 89 volunteers were informed about the objectives, procedures and potential risks of the 90 study. The project was approved by the research ethics committee of the 
A priori sample size calculation was obtained by the $\mathrm{G}^{*}$ Power $^{\circledR}$ 3.1.9.2 software with the ANCOVA test for fixed effects, main effects and interactions, using two groups, with effect size $0.6,5 \%$ alpha error and test power 1 - beta to 80 , which resulted in a total sample of 24 volunteers. The study included participants who had no history of resistance training in the last six months. The participants had no health problems and received clearance to participate from a physician. Exclusion criteria included acute or terminal musculoskeletal disease, skeletal muscle limitation that prevented the execution of the training protocol, severe cardiovascular disease, recent history of acute myocardial infarction, or any other medical contraindication for resistance training.

After recruitment, 62 individuals were selected according to the inclusion criteria, of which $17 \mathrm{did}$ not attend the initial meeting. The remaining 45 were assigned to the two training groups, 23 to the HST group and 22 to the TRT group. After loss of follow-up, 12 volunteers from the HST and 12 from the TRT group were reevaluated. The characteristics of the participants are shown in table 1.

\section{Experimental procedures}

The first two weeks of the study consisted of questionnaires, tests and retests and familiarization with the RT exercises ${ }^{1,21}$. All tests were performed between 14:00 and 16:00 hours. At the initial meeting, the researchers explained the research details and, if the participant agreed to participate they signed the free and informed 
130

131

132

consent form (ICF) and the International Physical Activity questionnaire (IPAQ www.ipaq.ki.se) was applied ${ }^{13}$.

The participants then initiated two weeks of RT familiarization. During the familiarization, two submaximal sets of ten to twelve repetitions were performed for each exercise (leg press $45^{\circ}$, deadlift, chest press and pulldown) at a self-selected load. Strength assessments, PFP tests and quality of life questionnaires were applied after the familiarization period and after the training period.

The tests involved i) ten maximum repetitions $(10 \mathrm{RM})$ in the leg press $45^{\circ}$ and chest press; ii) PFP assessment through the 30-second chair stand test, timed up and go (TUG) test ${ }^{33}$ and medicine ball throwing ${ }^{24}$; and iii) quality of life assessment using the SF-36 questionnaire. ${ }^{11}$ Additionally, 24-hour dietary recalls (two weekdays and one weekend) were applied. After initial testing, the participants performed eight weeks of either TRT or HST and were re tested five to seven days after the last training session.

\section{Strength tests}

At the beginning of the intervention, the 10RM tests were performed on the leg press $45^{\circ}$, deadlift, chest press and pulldown (Technogym ${ }^{\circledR}$, Biomedical Line, Gambettola, Italy) for subsequent load determination. Participants were instructed in the correct techniques for all exercises. The procedures were based on the recommendations described by Kraemer and Fry ${ }^{22}$. Participants warmed up with two sets of ten repetitions with a self-selected comfortable load. After three-minutes of rest, the estimated 10RM load was adjusted. If the volunteer could not perform ten repetitions or perform more than ten repetitions, the load was adjusted for the next attempt. Up to four attempts were allowed, with a four-minute break between each attempt. The tests were ceased when 
140 participants could not perform the movement properly (i.e. full range of motion without

141 relevant changes in technique).

142 Physical functional capacity tests

143

The 30-second chair stand involves the ability to sit and lift from a chair as

145 many times as possible in 30 seconds without using the arms in a single attempt ${ }^{33}$. The

146 TUG test consisted of moving from a seated position to a distance of 2.44 meters and

147 returning as quickly and comfortable as possible. Each participant had two attempts ${ }^{33}$.

148 The medicine ball throw (chest pass ) test consisted of three attempts of throwing a 1.5

$149 \mathrm{~kg}$ medicine ball as far as possible while sitting in a chair with the trunk supported ${ }^{24}$.

150 For TUG and medicine ball throw, the best score was used in the analysis.

\section{Quality of Life Questionnaire}

153

154

155

156

157

158

159

160

161

162

163

Quality of life was assessed using the SF-36 questionnaire ${ }^{11}$. The domains evaluated were: functional capacity, physical aspects, vitality, emotional aspects, social aspects, pain, general health status and health perception. The questionnaire was applied by the same evaluator pre and post intervention.

\section{Training protocol}

Exercise protocols were designed according to the minimum dose approach using multiarticular exercises ${ }^{15,18}$ as describe below. The eight weeks of training included a total of 16 training sessions divided into two training days/week. Each session lasted approximately 20 minutes. The program incorporated the following 
165

166

167

168

169

170 exercises: leg press $45^{\circ}$, deadlift, chest press and latissimus pulldown (Technogym ${ }^{\circledR}$, Biomedical Line, Gambettola, Italy), with 90-second recovery intervals between sets and exercises.

The HST group performed two sets of six to eight repetitions at 40 to $60 \%$ of 1RM (estimated by the Brzycki's equation ${ }^{5}$ ) during the 8 -week intervention. The concentric phase was performed as fast as possible and the eccentric phase was performed in two seconds (Total repetitions per exercise: $\cong 16$; Total seconds under tension per exercise: $\cong 24$ seconds). At all times, the participants were monitored by a trainer and strong encouragement was provided to ensure maximal concentric velocity. The TRT group performed two sets of 10 to 12 repetitions to momentary muscle failure, as defined by Steele et al. ${ }^{37}$, taking two seconds for the concentric and two seconds for the eccentric phase. During TRT, the load was adjusted whenever necessary to maintain the repetitions inside the proposed range (Total repetitions per exercise: $\cong 24$; Total seconds under tension per exercise: $\cong 48$ seconds). The supervision ratio was $1: 1$ for both groups (Table 1).

\section{Food Intake Assessment}

The participants were advised to maintain their normal eating habits and food intake over the period of the study. Dietary assessment was performed using six 24-hour food recalls, three in the first week and three in the last week of the study, compose of a weekend and two weekdays. The data collection method was standardized, as well as the conversion into home measurements and insertion in the food intake assessment software. 
Dietary data obtained from home measurements were converted to grams 190 and milliliters using a home measurement table ${ }^{27}$ for further analysis of dietary intake in 191 the Diet Pro Clinical ${ }^{\circledR}$ software, version 6.0, (Viçosa, Brazil), which results in total energy (kcal), macro and micronutrients (in grams). The National Nutrient Database of the United States Department of Agriculture ${ }^{42}$ and non-protein regional foods from the Brazilian Food Composition Table ${ }^{40}$ and of the Nutritional Composition Tables of the 195 Foods Consumed in Brazil ${ }^{3}$ were used to estimate protein consumption in grams.

Statistical analysis

198

Data normality was confirmed by the Shapiro-Wilk test. Data are presented as average \pm standard deviation. An independent $t$ test was performed to compare preintervention data between groups. A paired t test was performed to compare the preand-post intragroup differences. A covariance analysis (ANCOVA) compared the post intervention values of both groups using the initial values as covariates. An alpha level of $\mathrm{p}<0.05$ was accepted as of significance. Statistical analyzes were performed using Statistical Package for Social Sciences 17.0 software (SPSS, Chicago, IL). Interpretation of effect size between groups took place according to Cohen ${ }^{12}$ (confidence interval: 95\%) and were classified as: $\mathrm{d}<0.2$ as "trivial"; $\mathrm{d}>0.2-<0.5$ as "small"; $\mathrm{d}>0.5-<0.8$ as "medium" and $\mathrm{d}>0.8$ as large.

\section{Results}

All 24 elderly, completed all assessments and were included in the final 
214 observed during the study, except for protein intake that increased in the TRT $215 \operatorname{group}(\mathrm{p}=0.046)$ (Table 3).

Performance of the maximal and functional muscle strength tests are

217 presented in figures 1a to 3. Both groups showed significant improvements in the 10RM test in the leg press (HST 21\% and TRT 49\%) and effect size 0.74 (Figure 1a), with a significant difference between groups $(\mathrm{p}=0.019)$ in favor of the TRT group. The HST group did not significantly improve in the chest press $10 \mathrm{RM}$ test $(-0.6 \% \mathrm{p}=0.913)$, while the TRT group significantly increased the performance by $21 \%$ and effect size 0.85 , with a significant difference between groups $(\mathrm{p}=0.001)$ (Figure 1b), in favor of the TRT group.

There was a significant increase in TUG performance over time for both HST and TRT groups (Figure 2a). The HST group decreased the time by 7\%, and the TRT decreased the time by $10 \%$ and effect size 1.29 , with no significant difference $(p=0.300)$ between groups. Both groups exhibited significant improvements in the chair stand performance test (Figure 2b). The HST group increased the number of repetitions performed by $18 \%$ and the TRT by $21 \%$ and effect size 6.85 , with no significant difference $(p=0.081)$ between groups. Significant improvements were also observed in both groups for medicine ball throwing performances (Figure 3). The HST group increased the throwing capacity by $9 \%$ and the TRT by $9 \%$ and effect size 0.35 , with no difference between the groups $(\mathrm{p}=0.524)$.

Table 4 presents the values of the nine domains of the SF-36 quality of life 235 questionnaire. There was a significant change in the emotional aspect domain of $20 \%$ (p $236=0.042)$ in the HST and 50\% $(\mathrm{p}=0.043)$ in the TRT group following the intervention. 237 The only significant difference between the groups after the intervention was on pain, 238 with a greater improvement in the HST group compared to the TRT group ( $\mathrm{p}=0.006)$. 
240 Discussion

241

242

The present study aimed to compare and contrast the effects of TRT and

HST programs on PFP, muscle strength and quality of life in older adults. The main

244 findings of the study suggest that, aside from greater maximal strength increases after

245 TRT compared to HST, both groups achieved similar improvement in physical 246 functional capacity and quality of life.

The benefits of RT for the elderly and its importance for maintaining their 248 independence in daily life activities are already well established ${ }^{36}$. The present results reaffirm the benefits of resistance training for this population. Both groups significantly improved in all functionality tests performed, which is in agreement with previous findings $8,31,32,35$. Current data showed that eight weeks of RT, regardless of the HST or TRT methodology, was effective in improving most strength and functionality tests in older men and women ${ }^{36}$. The effects sizes obtained in the current study were generally moderate to high, which could be explained by the low initial values of the participants.

Prior to the study participants exhibited functional values lower than fitness reference values ${ }^{33}$. However, after the period of RT, there were significant improvements in TUG of $7.2 \%$ for HST and $10.1 \%$ in TRT, and chair stand of $18.1 \%$ for HST and $20.8 \%$ in TRT, placing them on average reference values for tests. By the end of the study, the mean for TUG and chair stand were above the reference values both for TRT and HST.

Previous studies have shown a superiority of HST over TRT in improving muscle function and power ${ }^{4,38}$. Different outcomes may be explained by the different method of determining and controlling loads and/or RT intensity. The high intensity RT 
264 efforts may be necessary to activate fast-twitch fibers, which are the most affected with 265 advancing age $\mathrm{e}^{17,25}$. Thus, the fact that RT is performed to failure may explain similar 266 results between HST and TRT and also why the present results were different from 267 those obtained in previous studies ${ }^{4,26}$. The superior strength gains observed in the TRT 268 in all exercises compared to the HST may be due to specificity, as the training 269 performed by the TRT was closer to the test protocol $^{6}$.

Prior research ${ }^{28-30}$ has shown a relationship between improved 271 neuromuscular performance and quality of life. Nevertheless, the present data did not 272 show a relationship between improved muscle performance and improved quality of 273 life.

However, there was improvement in both groups in the emotional aspect.

275 When performed at low intensity and high execution speed, RT has been show to result 276 in reduced pain perceptions, which might explain the more favorable result in this 277 domain in the HST group ${ }^{28}$. The TRT group presented an increase in the pain domain in 278 the SF-36 questionnaire, which might be due to the high intensity of effort associated 279 with TRT. The greater effort may have promoted greater inflammation and 280 consequently increased pain, as commonly reported with $\mathrm{TRT}^{14,34,39}$. It was not possible 281 to measure the extent to which pain interfered with the daily activities of participants, as 282 the other domains of quality of life did not worsen. However, this information may be 283 important for cases of people with chronic pain.

284 Our results suggest that both TRT and HST might have important practical 285 and clinical applications in increasing functionality in older people. Considering the 286 similarity in most functional parameters, the choice between the protocols should be 287 based on logistical and individual aspects, depending on the context. For example, when 288 there are limitations for training with high efforts, due to cardiovascular or 
musculoskeletal limitations, HST might be used. On the other hand, when the performance of high velocity exercises is not recommended, due to lack of coordination or poor movement quality, TRT might be preferable.

\section{Conclusion}

In summary, the present findings suggest that TRT and HST produce similar improvements in functional performance and quality of life in the elderly. However, TRT promoted greater increases in strength. Importantly, both interventions of RT were effective in promoting neuromuscular improvements and these benefits may contribute to greater independence and maintenance of daily life activities.

\section{Limitations and strengths}

composition, since this aspect may interfere with the relative strength gains. The heterogeneous sample may also have affected the interpretation of the results. The strengths of the study include the control of the intensity of the traditional group through repetition zones, the high 1:1 direct supervision, and dietary monitoring through food intake records. Although an increase of protein intake was observed in TRT group, both groups maintained the normal protein consumption during the intervention period. 


\section{References}

1. Adams KJ, Swank AM, Berning JM, Sevene-Adams PG, Barnard KL, ShimpBowerman J. Progressive strength training in sedentary, older African American women. Med Sci Sport Exerc. 2001;33(9):1567-1576.

2. Bamman MM, Hill VJ, Adams GR, et al. Gender Differences in ResistanceTraining-Induced Myofiber Hypertrophy Among Older Adults. Journals Gerontol Ser A. 2003;58(2):B108-B116. doi:10.1093/gerona/58.2.B108

3. Belchior Sé Marcia Maria Melo Quintslr M, Diretor-Executivo P, Miranda Milton de Arruda Martins H, Barbosa Patrícia Constante Jaime J, Rousseff Ministro da Saúde . Tabelas de Composição Nutricional Dos Alimentos Consumidos No Brasi. 2009

4. Bottaro M, Machado SN, Nogueira W, Scales R, Veloso J. Effect of high versus low-velocity resistance training on muscular fitness and functional performance in older men. Eur J Appl Physiol. 2007;99(3):257-264.

5. Brzycki M. Strength Testing-Predicting a One-Rep Max from Reps-to-Fatigue. J Phys Educ Recreat Danc. 1993;64(1):88-90. doi:10.1080/07303084.1993.10606684

6. Buckner SL, Jessee MB, Mattocks KT, et al. Determining Strength: A Case for Multiple Methods of Measurement. Sport Med. 2017;47(2):193-195. doi:10.1007/s40279-016-0580-3

7. Byrne C, Faure C, Keene DJ, Lamb SE. Ageing, Muscle Power and Physical Function: A Systematic Review and Implications for Pragmatic Training Interventions. Sport Med. 2016;46(9):1311-1332. doi:10.1007/s40279-016-0489$\mathrm{x}$

8. Cadore EL, Menger E, Teodoro JL, et al. Functional and physiological 
adaptations following concurrent training using sets with and without concentric failure in elderly men: A randomized clinical trial. Exp Gerontol. 2018;110:182190. doi:10.1016/j.exger.2018.06.011

9. Cadore EL, Pinto RS, Reischak-Oliveira Á, Izquierdo M. Explosive type of contractions should not be avoided during resistance training in elderly. Exp Gerontol. 2018;102(December 2017):81-83. doi:10.1016/j.exger.2017.12.003

10. Cadore EL, Rodríguez-Mañas L, Sinclair A, Izquierdo M. Effects of Different Exercise Interventions on Risk of Falls, Gait Ability, and Balance in Physically Frail Older Adults: A Systematic Review. Rejuvenation Res. 2013;16(2):105114. doi:10.1089/rej.2012.1397

11. Ciconelli RM [UNIFESP]. Tradução para o português e validação do questionário genérico de avaliação de qualidade de vida medical outcomes study 36-item short-form health survey (SF-36). Published online 1997. Accessed October 12, 2018. http://repositorio.unifesp.br/handle/11600/15360

12. Cohen J. Statistical Power Analysis for the Behavioral Sciences Second Edition. Accessed August 13, 2019. http://www.utstat.toronto.edu/ brunner/oldclass/378f16/readings/CohenPower.pd $\mathrm{f}$

13. Craig CL, Marshall AL, Sjöström M, et al. International Physical Activity Questionnaire: 12-Country Reliability and Validity. Med Sci Sport Exerc. 2003;35(8):1381-1395. doi:10.1249/01.MSS.0000078924.61453.FB

14. Fisher JP, Steele J. Heavier and lighter load resistance training to momentary failure produce similar increases in strength with differing degrees of discomfort. Muscle Nerve. 2017;56(4):797-803. doi:10.1002/mus.25537

15. Fisher JP, Steele J, Gentil P, Giessing J, Westcott WL. A minimal dose approach to resistance training for the older adult; the prophylactic for aging. Exp Gerontol. 2017;99(September):80-86. doi:10.1016/j.exger.2017.09.012

16. Fragala, MS, Cadore, EL, Dorgo, S, Izquierdo, M, Kraemer, WJ, Peterson, MD, and Ryan E. Resistance Training for Older Adults: Position Statement From the National Strength and Conditioning Association. J Strength Cond Res. 2019;33(8). doi:10.1519 / JSC.0000000000003230,

17. Gentil P, Hebling Campos M, Soares S, et al. Comparison of elbow flexor isokinetic peak torque and fatigue index between men and women of different training level. Eur J Transl Myol. 2017;27(4). doi:10.4081/ejtm.2017.7070 
18. Gentil P, Steele J, Fisher J. Why intensity is not a bad word - Benefits and practical aspects of high effort resistance training to the older. Clin Nutr. 2017;36(5):1454-1455. doi:10.1016/j.clnu.2017.05.024

19. Hunter GR, McCarthy JP, Bamman MM. Effects of Resistance Training on Older Adults. Sport Med. 2004;34(5):329-348. doi:10.2165/00007256-20043405000005

20. Hunter GR, Plaisance EP, Carter SJ, Fisher G. Why intensity is not a bad word: Optimizing health status at any age. Clin Nutr. 2018;37(1):56-60.

doi:10.1016/j.clnu.2017.02.004

21. Hunter GR, Wetzstein CJ, McLafferty Jr. CL, Zuckerman PA, Landers KA, Bamman MM. High-resistance versus variable-resistance training in older adults. Med Sci Sport Exerc. 2001;33(10):1759-1764.

22. Kraemer, W. J. Fry, AC. Strength testing: development and evaluation of methodology. In: Maud P, Foster C, eds. Physiological assessment of human fitness. Champaign, IL: Human Kinetics, 1995.

23. Lopez P, Pinto RS, Radaelli R, et al. Benefits of resistance training in physically frail elderly: a systematic review. Aging Clin Exp Res. 2018;30(8):889-899. doi:10.1007/s40520-017-0863-z

24. Marques MC, Tillaar R van den, Vescovi JD, González-Badillo JJ. Changes in Strength and Power Performance in Elite Senior Female Professional Volleyball Players During the In-Season: A Case Study. J Strength Cond Res. 2008;22(4):1147-1155. doi:10.1519/JSC.0b013e31816a42d0

25. Morton RW, Sonne MW, Farias Zuniga A, et al. Muscle fibre activation is unaffected by load and repetition duration when resistance exercise is performed to task failure. J Physiol. 2019;597(17):4601-4613. doi:10.1113/JP278056

26. Nogueira W, Gentil P, Mello SNM, Oliveira RJ, Bezerra AJC, Bottaro M. Effects of power training on muscle thickness of older men. Int J Sports Med. 2009;30(3):200-204. doi:10.1055/s-0028-1104584

27. Pinheiro ABV, Lacerda EMA, Benzecry EH, Gomes MCS CV. Tabela Para Avaliaçao de Consumo Alimentar Em Medidas Caseiras. 5a . Atheneu; 2009.

28. Ramirez-Campillo R, Alvarez C, Garcìa-Hermoso A, et al. High-speed resistance training in elderly women: Effects of cluster training sets on functional performance and quality of life. Exp Gerontol. 2018;110:216-222. doi:10.1016/j.exger.2018.06.014 
29. Ramirez-Campillo R, Díaz D, Martínez C, et al. Effects of different doses of high-speed resistance training on physical performance and quality of life in older women: a randomized controlled trial. Clin Interv Aging. 2016; Volume 11:1797-1804. doi:10.2147/CIA.S121313

30. Ramírez-Campillo R, Martínez C, de La Fuente CI, et al. High-Speed Resistance Training in Older Women: The Role of Supervision. J Aging Phys Act. 2017;25(1):1-9. doi:10.1123/japa.2015-0122

31. Reid KF, Martin KI, Doros G, et al. Comparative effects of light or heavy resistance power training for improving lower extremity power and physical performance in mobility-limited older adults. Journals Gerontol - Ser A Biol Sci Med Sci. 2015;70(3):374-380. doi:10.1093/gerona/glu156

32. Richardson DL, Duncan MJ, Jimenez A, Juris PM, Clarke ND. Effects of movement velocity and training frequency of resistance exercise on functional performance in older adults: a randomised controlled trial. Eur J Sport Sci. 2019;19(2):234-246. doi:10.1080/17461391.2018.1497709

33. Rikli RE, Jones CJ. Development and Validation of a Functional Fitness Test for Community-Residing Older Adults. J Aging Phys Act. 1999;7(2):129-161. doi:10.1123/japa.7.2.129

34. Santos WDN dos, Vieira CA, Bottaro M, et al. Resistance Training Performed to Failure or Not to Failure Results in Similar Total Volume, but With Different Fatigue and Discomfort Levels. J Strength Cond Res. Published online January 2019:1. doi:10.1519/jsc.0000000000002915

35. da Silva LXN, Teodoro JL, Menger E, et al. Repetitions to failure versus not to failure during concurrent training in healthy elderly men: A randomized clinical trial. Exp Gerontol. 2018;108:18-27. doi:10.1016/j.exger.2018.03.017

36. Silva NL, Oliveira RB, Fleck SJ, Leon ACMP, Farinatti P. Influence of strength training variables on strength gains in adults over 55 years-old: A meta-analysis of dose-response relationships. J Sci Med Sport. 2014;17(3):337-344. doi:10.1016/j.jsams.2013.05.009

37. Steele J, Fisher J, Giessing J, Gentil P. Clarity in reporting terminology and definitions of set endpoints in resistance training. Muscle Nerve. 2017;56(3):368374. doi:10.1002/mus. 25557

38. Straight CR, Lindheimer JB, Brady AO, Dishman RK, Evans EM. Effects of Resistance Training on Lower-Extremity Muscle Power in Middle-Aged and 
470

471

472

473

474

475

476

477

478

479

480

\section{5}

\section{7}

78

79

Older Adults: A Systematic Review and Meta-Analysis of Randomized

Controlled Trials. Sport Med. 2016;46(3):353-364. doi:10.1007/s40279-015-

$0418-4$

39. Stuart C, Steele J, Gentil P, Giessing J, Fisher JP. Fatigue and perceptual responses of heavier- and lighter-load isolated lumbar extension resistance exercise in males and females. PeerJ. 2018;6:e4523. doi:10.7717/peerj.4523

40. Tabela Brasileira de Composicao de Alimentos - TACO 4 Edicao Ampliada e Revisada.

41. Teodoro JL, da Silva LXN, Fritsch CG, et al. Concurrent training performed with and without repetitions to failure in older men: A randomized clinical trial. Scand J Med Sci Sport. 2019;29(8):1141-1152. doi:10.1111/sms.13451

42. UNITED STATES DEPARTMENT OF AGRICULTURE NATIONAL AGRICULTURAL STATISTICS SERVICE. Accessed May 14, 2019. https://www.nass.usda.gov/Publications/Ag_Statistics/2014/Ag Stats 2014_Complete Publication.pdf

(1)

9

70

71

72

73

74

76


Titles: Table 2. Initial characteristics of volunteers $(n=24)$

492 Captions: Table 2. ${ }^{\dagger}$ Obtained by Test $\mathrm{t}$; ${ }^{*} \mathrm{p} \leq 0.05$; SD: standard deviation; MET:

493 Metabolic equivalent;

494 Titles: Table 3. Pre and post food intake values of both groups

495 Captions: Table 3. ${ }^{1}$ Paired Student T test; ${ }^{2}$ ANCOVA: Covariance analysis; $†$ Difference 496 between post-moment groups; ${ }^{*} \mathrm{p}<0.05$; Effect size: size of made according to Cohen, 497 1988. And were classified as: $\mathrm{d}<0.2$ as "trivial"; $\mathrm{d}>0.2-<0.5$ as "small"; $\mathrm{d}>0.5-<0.8$ 498 as "medium" and $\mathrm{d}>0.8$ as large.

499 Titles: Table 4. Quality of life measured through the Medical Outcomes Study 36 - Item 500 short form health survey (SF-36)

501 Captions: Table 4. Paired Student T test; ${ }^{2}$ ANCOVA: Covariance analysis; ${ }^{\dagger}$ Difference 502 between post-moment groups; ${ }^{*} \mathrm{p}<0.05 ;{ }^{T}$ Effect size: size of made according to Cohen, 503 1988. And were classified as: $\mathrm{d}<0.2$ as "trivial"; $\mathrm{d}>0.2-<0.5$ as "small"; $\mathrm{d}>0.5-<0.8$ 504 as "medium" and d> 0.8 as large. 
506 Captions: Figure 1a: Difference in $(\mathrm{kg})$ in Leg press; Figure 1b: Difference in $(\mathrm{kg})$ in

507 Chest press; Figure 2a: Difference in (s) in TUG (timed-up-and-go); s:seconds; Figure

508 2b: Difference in (rep) Chair Stand; rep: repetitions; Figure 3: Difference in (cm)

509 Medicine ball; cm: centimeters; p: Covariance analysis; EF: effect size

510

511

512 Table 1. Training Protocol

\begin{tabular}{lcc}
\cline { 1 - 1 } & HST & TRT \\
\cline { 1 - 1 } Training period & 8 weeks & 8 weeks \\
Frequency & $2 \mathrm{x}$ & $2 \mathrm{x}$ \\
Session duration & $\cong 20 \mathrm{~min}$ & $\cong 20 \mathrm{~min}$ \\
Training load & 40 to $60 \% 1 \mathrm{RM}$ & $10-12$ rep. max. \\
Execution speed & Concentric: As fast as possible & Concentric: 2 second \\
& Eccentric: 2 second & Eccentric: 2 second \\
Recovery interval & 90 -second & 90 -second \\
Exercises & leg press $45^{\circ}$, deadlift, chest press and latissimus pulldown \\
Supervision & \multicolumn{2}{|}{$1: 1$} \\
\end{tabular}

516 Table 2. Initial characteristics of volunteers $(n=24)$

\begin{tabular}{lccc}
\hline & HST $(\mathrm{n}=12)$ & TRT $(\mathrm{n}=12)$ & \\
\cline { 2 - 3 } & Mean \pm SD & Mean \pm SD & $\mathbf{p}^{\dagger}$ \\
\hline Age (years) & $69.4 \pm 6.0$ & $63.3 \pm 7.1$ & 0.269 \\
MET/min/week & $894.8 \pm 995.7$ & $861.6 \pm 759.6$ & 0.928 \\
Body mass (Kg) & $70.5 \pm 10.7$ & $68.8 \pm 7.5$ & 0.284
\end{tabular}


Table 3. Pre and post food intake values of both groups

\begin{tabular}{|c|c|c|c|c|c|c|c|c|c|c|c|}
\hline & \multicolumn{4}{|c|}{ HST } & \multicolumn{4}{|c|}{ TRT } & \multirow[b]{2}{*}{$\Delta p$} & \multirow[b]{2}{*}{$\begin{array}{c}\text { Effect } \\
\operatorname{size}^{T}\end{array}$} & \multirow[b]{2}{*}{$\mathrm{ANCOVA}^{2}$} \\
\hline & Pre & Post & $\mathbf{p}^{1}$ & $\begin{array}{c}\text { Effect } \\
\text { size }\end{array}$ & Pre & Post & $\mathbf{p}^{1}$ & $\begin{array}{c}\text { Effect } \\
\text { size }\end{array}$ & & & \\
\hline calories & $1274.3 \pm 364.9$ & $1332.6 \pm 521.5$ & 0.526 & & $1444.7 \pm 536.5$ & $1476.7 \pm 411.6$ & 0.840 & & 0.8 & 0.3 & 0.781 \\
\hline (kcal) & & & & 0.1 & & & & 0.0 & & & \\
\hline Carbohydrates (g) & $164.3 \pm 69.9$ & $205.4 \pm 103.5$ & 0.159 & 0.5 & $432.1 \pm 885.3$ & $197.3 \pm 113.6$ & 0.530 & -0.2 & 0.2 & 0.0 & 0.717 \\
\hline Protein $(\mathrm{g})$ & $53.9 \pm 19.3$ & $49.9 \pm 12.7$ & 0.437 & -0.2 & $58.7 \pm 17.6$ & $68.2 \pm 196.5$ & 0.433 & 3.3 & 0.2 & 0.4 & 0.072 \\
\hline Protein $(\mathrm{g} / \mathrm{kg})$ & $0.7 \pm 0.3$ & $0.7 \pm 0.1^{\dagger}$ & 0.332 & -0.2 & $0.8 \pm 0.2$ & $0.9 \pm 0.3^{\dagger}$ & 0.396 & 0.4 & 0.2 & 0.9 & $0.046^{*}$ \\
\hline $\mathrm{BCAA}(\mathrm{g})$ & $3.3 \pm 1.6$ & $2.5 \pm 1.4$ & 0.215 & -0.4 & $2.8 \pm 1.2$ & $3.7 \pm 2.2$ & 0.144 & 0.6 & 0.0 & 0.0 & 0.082 \\
\hline Lipids (g) & $44.9 \pm 14.5$ & $52.1 \pm 23.0$ & 0.242 & 0.4 & $49.0 \pm 16.0$ & $55.0 \pm 13.7$ & 0.238 & 0.3 & 0.8 & 0.1 & 0.926 \\
\hline Calcium (mg) & $415.0 \pm 159.2$ & $383.2 \pm 166.6$ & 0.212 & -0.2 & $519.0 \pm 190.0$ & $509.9 \pm 219.2$ & 0.754 & -0.0 & 0.7 & 0.6 & 0.409 \\
\hline Dietary fiber $(\mathrm{g})$ & $9.8 \pm 3.6$ & $11.9 \pm 4.3$ & 0.052 & 0.5 & $10.1 \pm 3.4$ & $10.1 \pm 5.3$ & 0.997 & 0.0 & 0.1 & 0.3 & 0.218 \\
\hline
\end{tabular}


Table 4. Quality of life measured through the Medical Outcomes Study 36 - Item short form health survey (SF-36)

\begin{tabular}{|c|c|c|c|c|c|c|c|c|c|c|c|}
\hline \multirow[b]{2}{*}{ Domains } & \multicolumn{4}{|c|}{ HST } & \multicolumn{4}{|c|}{ TRT } & \multirow[b]{2}{*}{$\Delta \mathbf{p}$} & \multirow[b]{2}{*}{$\begin{array}{c}\text { Effect } \\
\text { size }^{T}\end{array}$} & \multirow[b]{2}{*}{$\mathrm{ANCOVA}^{2}$} \\
\hline & Pre & Post & $\mathbf{p}^{1}$ & $\begin{array}{c}\text { Effect } \\
\text { size }\end{array}$ & Pre & Post & $\mathbf{p}^{1}$ & $\begin{array}{c}\text { Effect } \\
\text { size }\end{array}$ & & & \\
\hline Functional capacity & $75.4 \pm 20.7$ & $78.3 \pm 19.9$ & 0.354 & 0.1 & $82.0 \pm 13.5$ & $89.5 \pm 10.3$ & 0.107 & 0.5 & 0.4 & 0.6 & 0.162 \\
\hline Physical aspects & $68.7 \pm 41.4$ & $83.3 \pm 30.7$ & 0.167 & 0.3 & $75.0 \pm 36.9$ & $77.0 \pm 39.1$ & 0.865 & 0.0 & 0.5 & 0.1 & 0.606 \\
\hline Emotional aspect & $69.4 \pm 36.1$ & $83.3 \pm 33.3$ & $0.042 *$ & 0.3 & $61.1 \pm 42.2$ & $91.6 \pm 28.8$ & $0.043 *$ & 0.7 & 0.9 & 0.2 & 0.343 \\
\hline Vitality & $64.5 \pm 15.2$ & $68.3 \pm 12.4$ & 0.324 & 0.2 & $66.6 \pm 24.2$ & $73.7 \pm 14.0$ & 0.397 & 0.2 & 0.6 & 0.6 & 0.350 \\
\hline Emotional aspects & $70.3 \pm 12.5$ & $73.0 \pm 12.4$ & 0.560 & 0.2 & $67.4 \pm 21.9$ & $73.3 \pm 15.1$ & 0.414 & 0.2 & 0.6 & 0.0 & 0.807 \\
\hline Social aspects & $82.2 \pm 18.0$ & $84.3 \pm 24.4$ & 0.631 & 0.1 & $84.4 \pm 14.2$ & $92.7 \pm 14.5$ & 0.150 & 0.5 & 0.9 & 0.4 & 0.352 \\
\hline Pain & $76.4 \pm 29.8$ & $85.8 \pm 21.4$ & 0.341 & 0.3 & $72.2 \pm 26.7^{\dagger}$ & $59.3 \pm 20.6^{\dagger}$ & 0.157 & -0.4 & 0.8 & -1.2 & $0.006^{*}$ \\
\hline General health & $69.1 \pm 19.9$ & $72.5 \pm 22.7$ & 0.205 & 0.0 & $72.5 \pm 18.7$ & $72.1 \pm 13.8$ & 0.918 & -0.0 & 0.5 & 0.0 & 0.616 \\
\hline Health perceptions & $62.5 \pm 19.9$ & $70.8 \pm 25.7$ & 0.234 & 0.4 & $60.4 \pm 16.7$ & $62.5 \pm 19.9$ & 0.655 & 0.1 & 0.6 & 0.3 & 0.409 \\
\hline
\end{tabular}


Fig: 1a

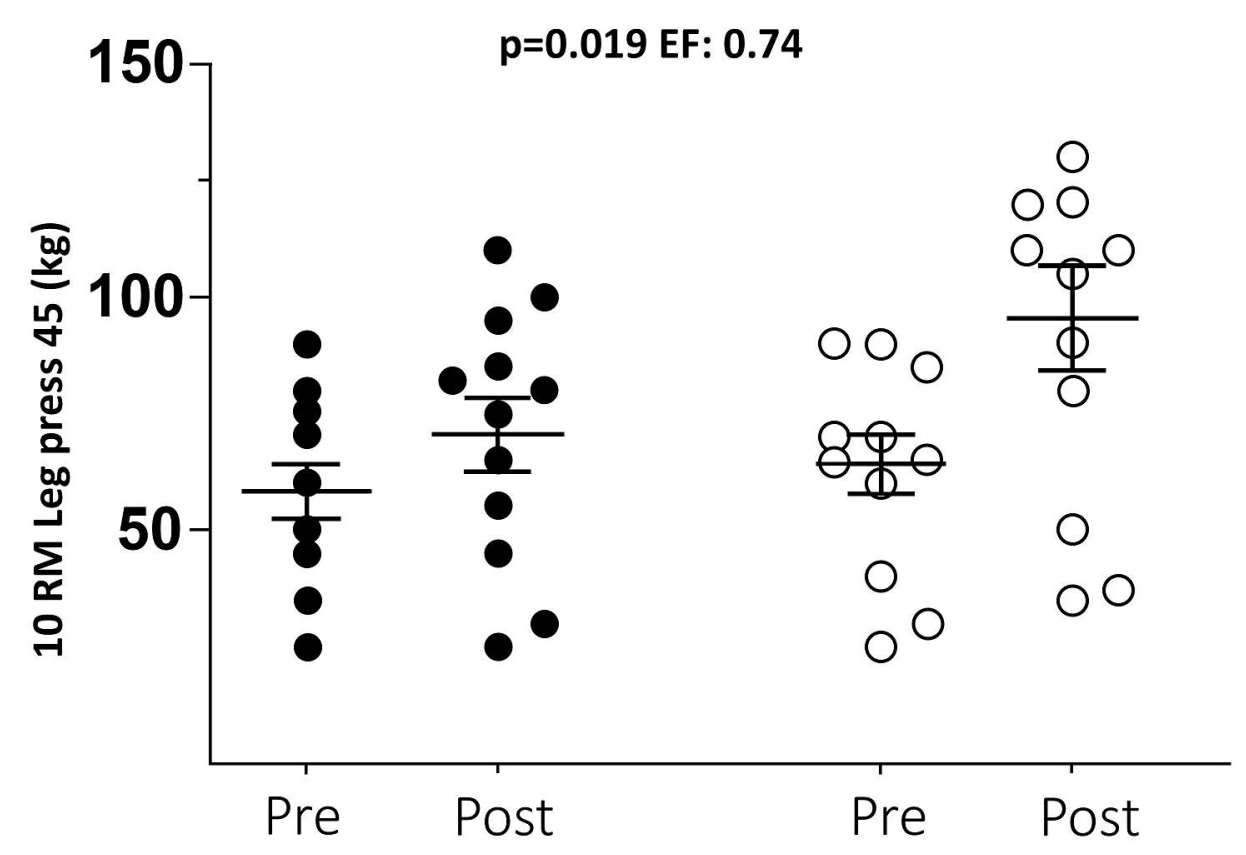

Fig: $1 b$

- HST

O TRT

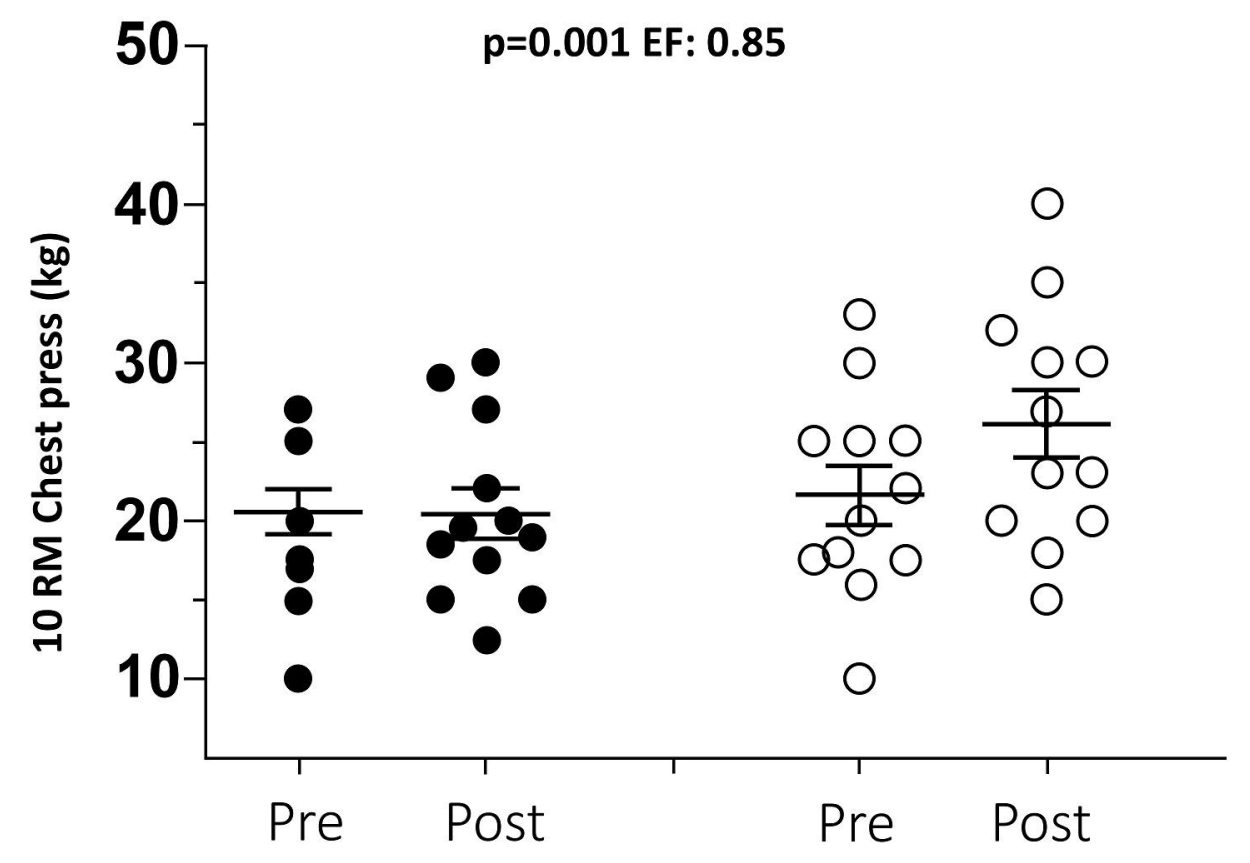


Fig: $2 a$

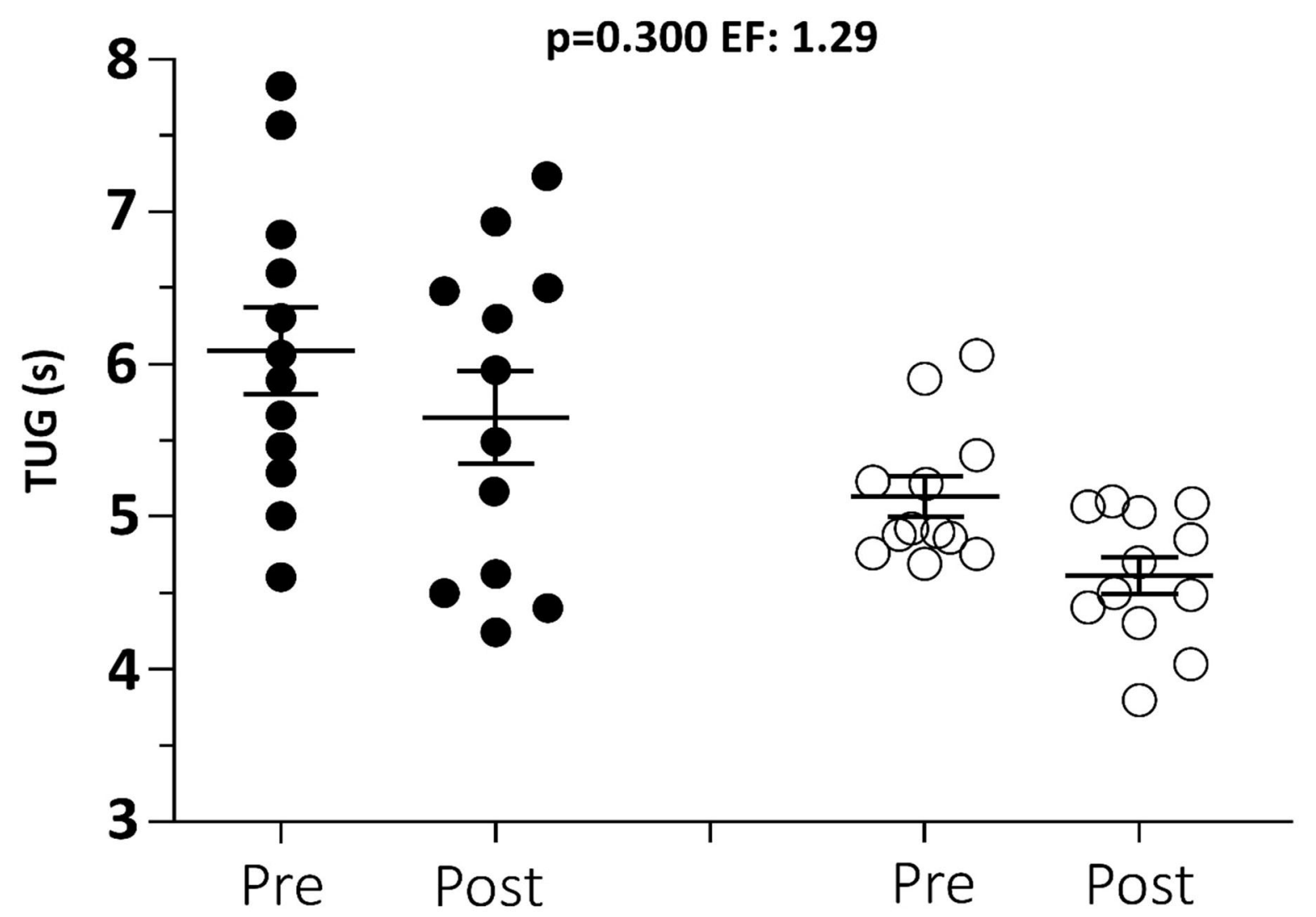

Fig: $2 b$

- HST

$\bigcirc$ TRT

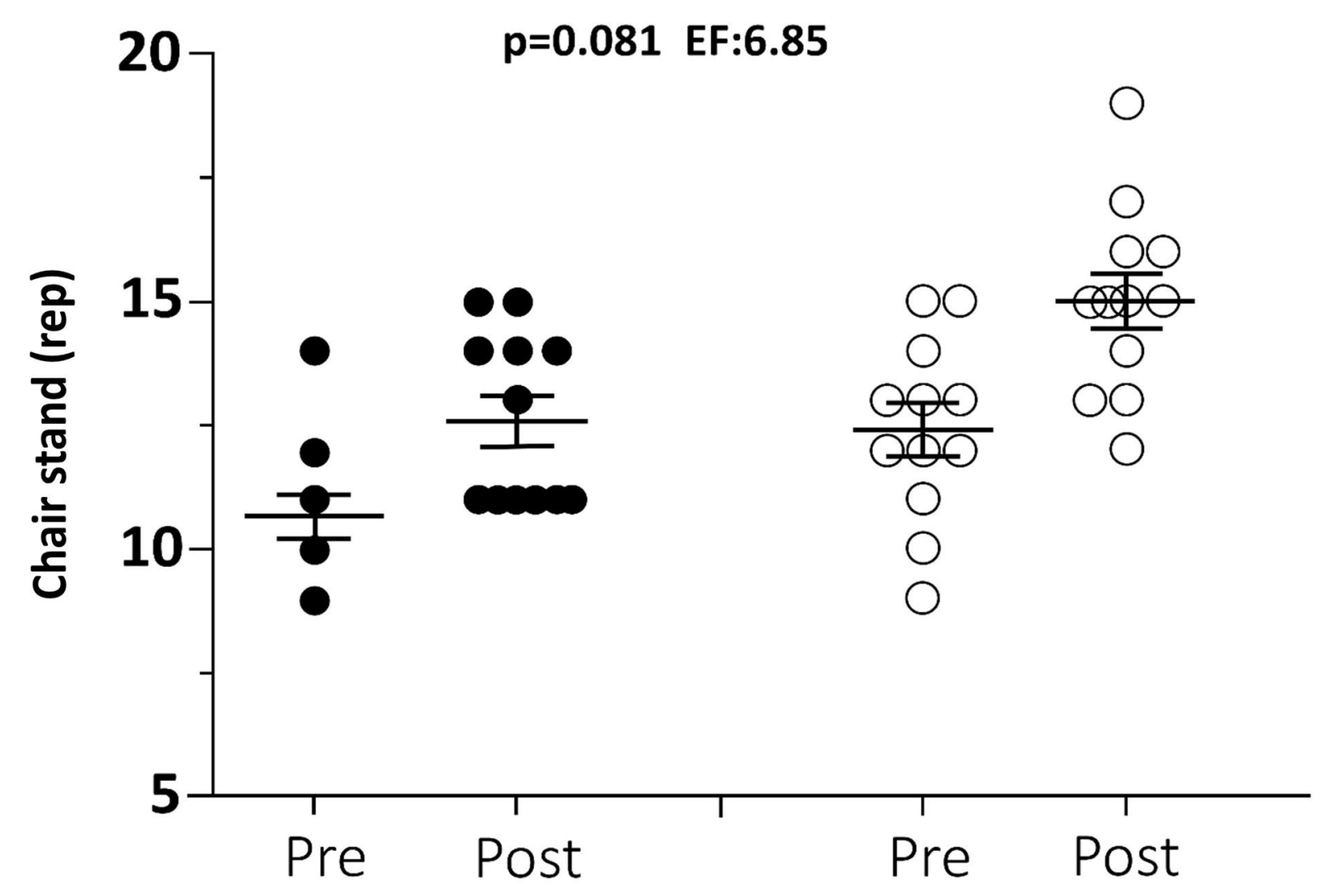


Fig: 3

- HST

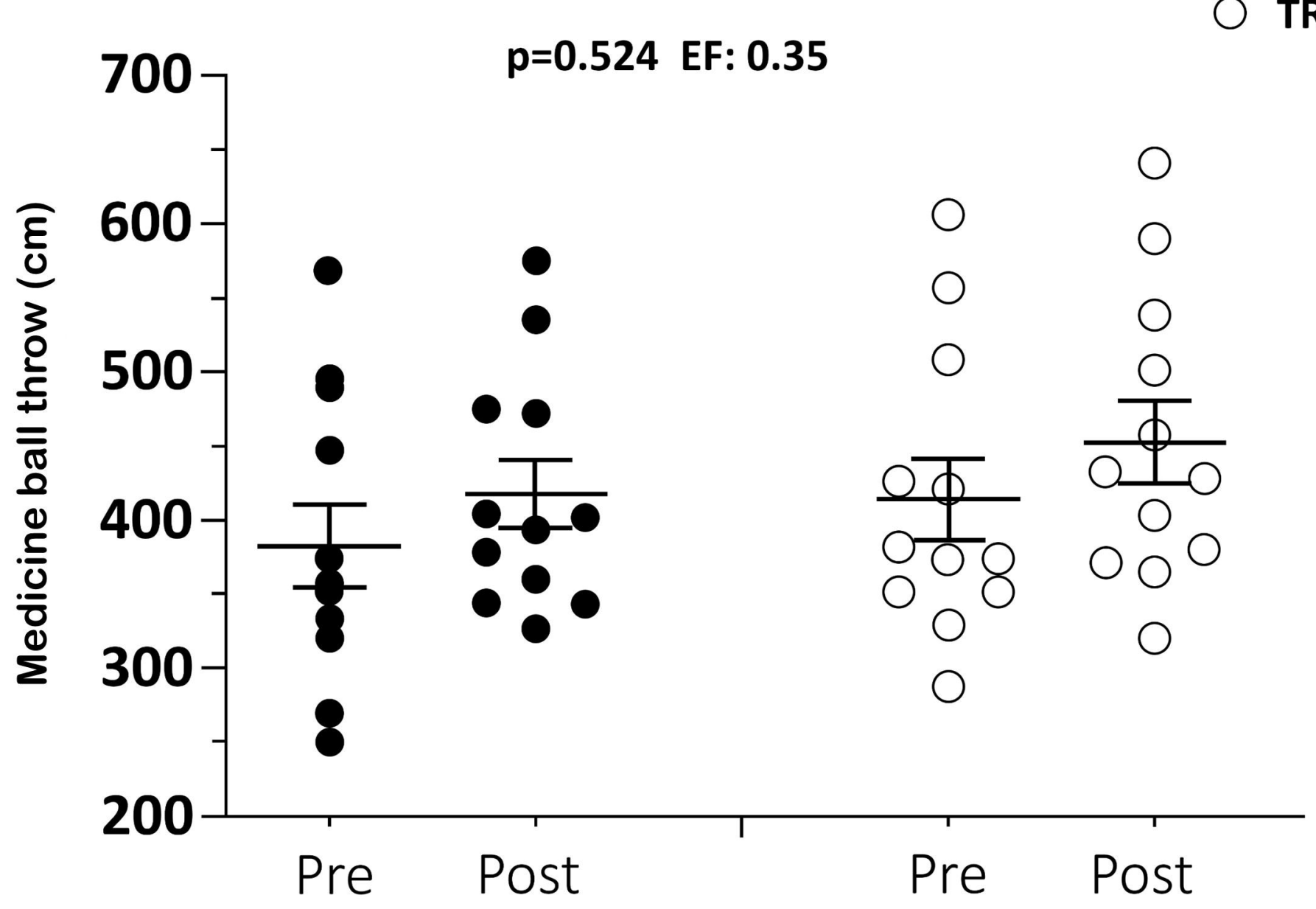

